\title{
THE CYBERSPACE IN THE CONTINUED CLINICAL BIOCHEMISTRY EDUCATION
}

Martins, J.M. ${ }^{1}$, Maia, W.B. ${ }^{1}$, Aquino, I.J. ${ }^{1}$, Silva, L.G.C. ${ }^{1}$, Porto, A.L.F. ${ }^{2}$, Paes, C.F.C.G. ${ }^{1}$, Paiva, A.L.A. ${ }^{1}$

${ }^{1}$ UFPE; ${ }^{2}$ UFRPE

The cybernetic spaces simulate the real world with interactive multimedia. This work has been applied since January, 2007 on the curricular student's apprenticeship at high school and graduation, in the site "bioq.educacao.biz/ULAB-HC-UFPE". It has been developed to provide continuity to the technical-scientific learning of students and professionals, and also to improve their human social relations on the labour environment. It's comprises a virtual space, destined to communication and collective building of knowledge on the clinical biochemistry. It's about an interactive environment which allows the users registered as coordinator professor (professional) or the scientist student (trainee), unlimited access to posting contents (classes, texts, presentations, animations), consultations, non-synchronic discussions (on orkut, forums, e-mail) and synchronic discussions (on chats, videoconferences). After a few live tutorials about new input in this environment, and the use of the new learning tool, the collective building of knowledge on cyberspace begins. As a trainee's program task, the scientist student would have to build a space of his own, under guidance and supervision of the coordinator teachers. The cyberspace efficiency was evaluated from reports collected in February, 2008: the adherence to this work was satisfactory, regarding this period, with 68 registered users, 870 accesses and 52 contents available on the several sections of the virtual laboratory. Our work is still being applied, and new adhesions are happening everyday. We intend to amplify this cyber environment in order to make it a permanent continued education site on the health area. From interest contracts and common knowledge, the technological interfaces constitute an interaction, in which everyone is a potential author.

Keywords: Cyberspace, online biochemistry education, continued education. 